\title{
DPP-4 inhibitor and alpha-glucosidase inhibitor equally improve endothelial function in patients with type 2 diabetes: EDGE study
}

Kazufumi Nakamura ${ }^{1 *}$, Hiroki Oe ${ }^{1}$, Hajime Kihara ${ }^{2}$, Kenei Shimada ${ }^{3}$, Shota Fukuda ${ }^{4}$,Kyoko Watanabe ${ }^{5}$, Tsutomu Takagi ${ }^{6}$, Kei Yunoki ${ }^{1}$, Toru Miyoshi ${ }^{1}$, Kumiko Hirata ${ }^{7}$, Junichi Yoshikawa ${ }^{8}$ and Hiroshi Ito ${ }^{1 *}$

\begin{abstract}
Background: Alpha glucosidase inhibitor (Gl) attenuates postprandial hyperglycemia (PPH) and reduces the risk of cardiovascular events in patients with impaired glucose tolerance or type 2 diabetes. Dipeptidyl peptidase 4 (DPP-4) inhibitors also attenuate PPH. PPH is one of the factors leading to endothelial dysfunction which is an early event in the pathogenesis of atherosclerosis. Furthermore, DPP-4 inhibitors protect endothelial function through a GLP-1-dependent mechanism. However, the impact of these two types of drugs on endothelial dysfunction in patients with type 2 diabetes has not been fully elucidated. We compared the effects of sitagliptin, a DPP-4 inhibitor, and voglibose, an alpha Gl, on endothelial function in patients with diabetes.
\end{abstract}

Methods: We conducted a randomized prospective multicenter study in 66 patients with type 2 diabetes who did not achieve the treatment goal with sulfonylurea, metformin or pioglitazone treatment; 31 patients received sitagliptin treatment and 35 patients, voglibose treatment. The flow-mediated dilatation (FMD) of the brachial artery was measured in the fasting state at baseline and after 12 weeks of treatment. The primary endpoint was a change in FMD ( $\triangle F M D$ ) from the baseline to the end of follow-up. The effects of sitagliptin and voglibose on FMD were assessed by ANCOVA after adjustment for the baseline FMD, age, sex, current smoking, diabetes duration and body mass index. Secondary efficacy measures included changes in HbA1c, GIP, GLP-1, C-peptide, CD34, lipid profile, oxidative stress markers, inflammatory markers and eGFR and any adverse events.

Results: $\triangle F M D$ was significantly improved after 12 weeks of treatment in both groups, and there was no significant difference in $\triangle F M D$ between the two groups. There were no significant differences in changes in HbA1c, GIP, GLP-1, C-peptide, lipid profile, oxidative stress marker, inflammatory marker and eGFR between the two groups. Compared with voglibose, sitagliptin significantly increased the circulating CD34, a marker of endothelial progenitor cells. Adverse events were observed in 5 patients in only the voglibose group (diarrhea 1, nausea 1, edema 2 and abdominal fullness 1).

Conclusions: Sitagliptin improved endothelial dysfunction just as well as voglibose in patients with type 2 diabetes. Sitagliptin had protective effects on endothelial function without adverse events.

Trial registration: registered at http://www.umin.ac.jp/ctrj/ under UMIN000003951

Keywords: Dipeptidyl peptidase 4 (DPP-4) inhibitors, Alpha glucosidase inhibitor, Endothelial function, Flow-mediated dilatation, CD34

\footnotetext{
* Correspondence: ichibun@cc.okayama-u.ac.jp; itomd@md.okayama-u.ac.jp

'Department of Cardiovascular Medicine, Okayama University Graduate

School of Medicine, Dentistry and Pharmaceutical Sciences, 2-5-1

Shikata-cho, Okayama 700-8558, Japan

Full list of author information is available at the end of the article
} 


\section{Introduction}

Postprandial hyperglycemia ( $\mathrm{PPH}$ ) plays a major role in cardiovascular complications in patients with type 2 diabetes [1] and impaired glucose tolerance (IGT) [2]. $\mathrm{PPH}$ is one of the main factors leading to endothelial dysfunction, which is an early event in the pathogenesis of atherosclerosis $[3,4]$.

Alpha glucosidase inhibitor (GI) prevents the digestion of carbohydrates including starch and table sugar, attenuates postprandial hyperglycemia [5] and delays the development of type 2 diabetes in patients with IGT [6]. Miglitol, an alpha GI, improves endothelial dysfunction assessed by the response of forearm blood flow to reactive hyperemia and flow-mediated dilatation (FMD) in patients with type 2 diabetes and coronary artery disease $[7,8]$. Acarbose, an alpha GI, improves postprandial endothelial dysfunction in patients with type 2 diabetes $[9,10]$ and reduces the risk of cardiovascular events in patients with type 2 diabetes [11] and IGT [12,13].

Dipeptidyl peptidase 4 (DPP-4) inhibitor enhances endogenous incretin action and promotes glucose-dependent insulin secretion. Thus, DPP-4 inhibitor attenuates postprandial hyperglycemia [14]. Furthermore, glucagon-like peptide-1 (GLP-1), an incretin, induces an endothelialdependent relaxation via NO-dependent action [15] and improves endothelial dysfunction in patients with type 2 diabetes [16], and sitagliptin, a DPP-4 inhibitor, protects endothelial function in spontaneously hypertensive rats through a GLP-1-dependent mechanism [17]. However, the impact of these two types of drugs on endothelial dysfunction in patients with type 2 diabetes has not been fully elucidated and has been controversial $[18,19]$.

We conducted a randomized prospective multicenter study to compare the effects of sitagliptin, a DPP-4 inhibitor, and voglibose, an alpha GI, on endothelial function assessed by FMD in patients with type 2 diabetes.

Liao et al. reported that number of circulating endothelial progenitor cells (EPCs) in patients with type 2 diabetes was significantly lower than that in the healthy subjects, treatment with metformin significantly increased EPCs and the EPCs number was related to endothelial function assessed by FMD [20]. Fadini et al. reported that sitagliptin increased circulating EPCs in type 2 diabetic patients [21]. We also compared the effects of sitagliptin and voglibose on number of circulating EPCs assessed by measurement of CD34, a maker of EPCs [22], postive cells in patients with type 2 diabetes in this study.

DPP-4 inhibitors have anti-inflammatory and antioxidative effects [23-25]. Ishibashi et al. reported that linagliptin inhibited the generation of reactive oxygen species induced by advanced glycation end products (AGEs) in endothelial cells [23]. Matsubara et al. reported that sitagliptin improves endothelial dysfunction in association with ant-inflammatory effects in patients with coronary artery disease and uncontrolled diabetes [24]. Shiraki et al. reported that GLP-1 reduced TNF- $\alpha$ induced oxidative stress in endothelial cells [25]. We also measured levels of inflammatory markers, including high-sensitivity $\mathrm{C}$-reactive protein (hs-CRP) and pentraxin-3 (PTX-3), and oxidative stress markers, including malondialdehyde-modified low-density lipoprotein (MDA-LDL) and urine 8-hydroxy-2'-deoxyguanosine (8-OHdG).

The primary endpoint in this study was a sitagliptinor voglibose-induced change in FMD $(\triangle F M D)$ from baseline to the end of follow-up. Secondary efficacy measures included changes in HbA1c, gastric inhibitory peptide (GIP), GLP-1, C-peptide, CD34, lipid profile, adiponectin, oxidative stress markers including MDA-LDL and urine $8-\mathrm{OHdG}$, inflammatory markers including hsCRP and PTX-3, and estimated glomerular filtration rate (eGFR) and any adverse events.

\section{Methods}

\section{Study populations}

We conducted a randomized prospective multicenter study in patients with type 2 diabetes who did not achieve the treatment goal with diet, exercise, sulfonylurea, metformin or pioglitazone treatment. We recruited 66 patients (men and women) who were from 20 to 85 years of age. Thirty-one patients received the sitagliptin $(50 \mathrm{mg} /$ day $)$ treatment and 35 patients, the voglibose $(0.6 \mathrm{mg} /$ day) treatment. The doses of the two drugs used in this study are recommended therapeutic doses for Japanese $[26,27]$ and the doses are covered by the Japanese National Health Insurance. The exclusion criteria were as follows: treatment with insulin, alpha GI or glinide, type 1 diabetes, HbA1c $\geq 9.0 \%$, systolic blood pressure $\geq 160 \mathrm{mmHg}$ and serum creatinine $\geq 1.5 \mathrm{mg} / \mathrm{dL}$ at baseline. The study protocol was approved by the Ethics Committee of Okayama University Graduate School of Medicine, Dentistry, and Pharmaceutical Sciences, and written informed consent was obtained from all patients before any study procedure was undertaken.

\section{Study protocol}

The patients were followed for at least 8 weeks to confirm that they did not achieve the treatment goal with diet, exercise, sulfonylurea, metformin or pioglitazone treatment. The patients were prospectively randomly assigned to additional treatment with either sitagliptin $(50 \mathrm{mg} /$ day $)$ or voglibose $(0.6 \mathrm{mg} /$ day $)$ for 12 weeks (Figure 1). The flow-mediated dilatation (FMD) of the brachial artery was measured in the fasting state at baseline and after 12 weeks of the treatment. Blood and urine tests were also performed at baseline and at the end of the study. The patients' antihypertensive, 


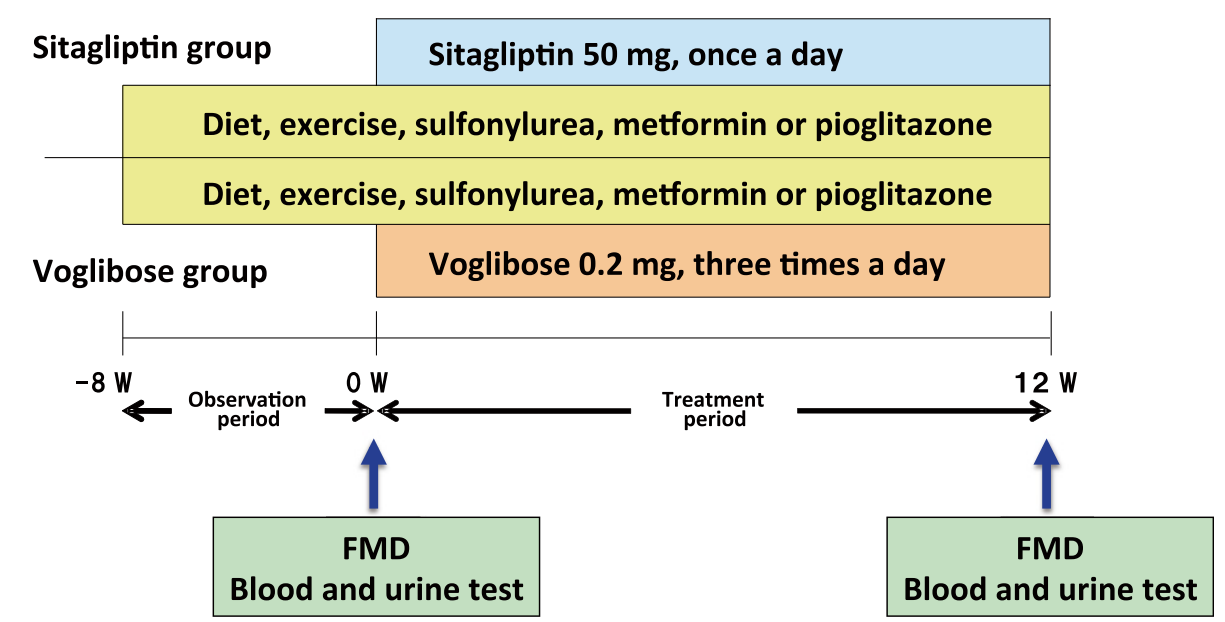

Figure 1 Study protocol. The patients were followed for at least 8 weeks to confirm that they did not achieve the treatment goal. The patients were prospectively, randomly assigned to additional treatment with either sitagliptin ( $50 \mathrm{mg} /$ day) or voglibose $(0.6 \mathrm{mg} /$ day) for 12 weeks. Measurements of flow-mediated dilatation (FMD) of the brachial artery and blood and urine tests were performed in the fasting state at baseline and after 12 weeks of treatment.

antihyperlipidemic and antidiabetic drugs were not changed and anti-oxidant drugs, including vitamin $\mathrm{C}$ and $\mathrm{E}$, were not added throughout the study period.

\section{Measurements of biochemical parameters}

The following parameters were measured at baseline and after 12 weeks of treatment: complete blood count, liver function test including measurement of AST, ALT and $\mathrm{LDH}$, renal function test including measurement of $\mathrm{BUN}$, creatinine, $\mathrm{Na}, \mathrm{K}$ and $\mathrm{Cl}, \mathrm{HbA1c}$, gastric inhibitory peptide (GIP), GLP-1, C-peptide, CD34, lipid profile including total cholesterol, triglyceride, and high-density lipoprotein (HDL-C), adiponectin, oxidative stress markers including MDA-LDL and urine 8-OHdG, inflammatory markers including hs-CRP and PTX-3, and estimated glomerular filtration rate (eGFR). HbA1c levels were measured using high-performance liquid chromatography. The number of CD34+ cells was determined by flow cytometry using FITC-labeled CD45 and phycoerythrin (PE)-labeled CD34 antibodies (BD Biosciences). eGFR $\left(\mathrm{mL} / \mathrm{min} / 1.73 \mathrm{~m}^{2}\right)$ was determined by the modified Modification of Diet and Renal Disease study formula (MDRD) for Japanese: eGFR $=194 \times\left(\mathrm{age}^{-0.287}\right) \times$ $\left(\right.$ serum creatinine $\left.{ }^{-1.094}\right) \times(0.739$ if female $)$ [28]. These measurements were performed by SRL Company, Ltd. (Tokyo, Japan).

\section{Flow-mediated dilation (FMD)}

Endothelium-dependent dilation was assessed as a parameter of vasodilation according to the guidelines for ultrasound assessment of FMD of the brachial artery in the fasting state [29]. Using a $10-\mathrm{MHz}$ linear-array transducer probe (Unex Company Ltd., Nagoya, Japan), longitudinal images of the brachial artery at baseline were recorded with a stereotactic arm, and measurements of the artery diameter were made after supine rest for $\geq 5 \mathrm{~min}$ as previously described [30-32]. The diameter of the artery was measured from clear anterior (media-adventitia) and posterior (intima-media) interfaces, which were manually determined. Then, suprasystolic compression (50 $\mathrm{mmHg}$ higher than systolic blood pressure) was performed at the right forearm for $5 \mathrm{~min}$, and measurements of the artery diameter were made continuously from $30 \mathrm{sec}$ before to $\geq 2 \mathrm{~min}$ after cuff release. Maximum vasodilation was then evaluated from the change in artery diameter after the release of occlusion (\%FMD). FMD is known to be affected by a wide range of biological, environmental, and methodological factors [33]. To quantify inter- and intra-observer reproducibility, baseline brachial diameter and FMD were measured by three individuals in Okayama University Hospital. Interand intra-observer coefficients were high $(r>0.90)$.

\section{Statistical analysis}

The results are expressed as mean $\pm \mathrm{SD}$. We assumed that FMD increased by $2 \%$ in sitagliptin group and decreased by $0.5 \%$ in voglibose group with a standard deviation of $3 \%$. A minimum sample size of 24 participants in each group was required to detect statistical differences in FMD with a power of $80 \%$ and $\alpha$ error of $5 \%$. The effects of sitagliptin and voglibose on FMD were assessed by ANCOVA after adjustment for the baseline FMD, age, sex, current smoking, diabetes duration and body mass index (BMI). Differences in age, sex, BMI and abdominal girth were compared using Student's t-test. The duration of diabetes was 
compared using the Wilcoxon rank sum test and categorical variables, using Fisher's exact test. Differences in secondary efficacy measures between baseline and 12 weeks were compared using the paired Student's ttest. Values of $\mathrm{P}<0.05$ were considered to be statistically significant.

\section{Results}

\section{Baseline characteristics}

Although 66 patients with type 2 diabetes were enrolled in this study between September 2010 and December 2011, 6 patients were excluded from this study (4 protocol violation at baseline and 2 withdrawal of consent). During the follow-up period, 5 patients with hypertension dropped out of the study due to change of concomitant antihypertensive drugs. The follow-up study was completed in 55 (83\%) of the patients; 24 patients received the sitagliptin treatment and 31 patients, the voglibose treatment. The data collection was completed in July 2012. Baseline characteristics, including age, sex, BMI and the type of anti-diabetic medication are shown in Table 1. It has been reported that endotheliumdependent vasodilation assessed by FMD declines with advance of age $[34,35]$. We recruited men and women who were from 20 to 85 years of age. The age range was quite wide in our study, but there was no significant difference in age or baseline FMD between the two groups (age, sitagliptin: $66.6 \pm 11.9,>70$ years: 12 , median 69.5, range: $37-84$ versus voglibose: $68.4 \pm 9.2$, >70 years: 14 , median 70.0 , range: 48 - 80 years old, $\mathrm{P}=0.529$, Table 1) (baseline FMD, sitagliptin: $5.41 \pm 2.25$ versus voglibose: $4.96 \pm 2.16 \%, \mathrm{P}=0.450$, Table 2 ). We did not exclude patients with severe dyslipidemia, but there were no significant differences in use of antihyperlipidemic drugs (Table 1) and baseline total cholesterol, triglyceride and HDL-C (Table 3) between the two groups. No patients died, developed cardiovascular events or were admitted to the hospital during the course of the study.

\section{The primary endpoint}

Change in FMD ( $\triangle$ FMD) was significantly improved after 12 weeks of treatment in both groups (sitagliptin: +1.11 , 95\% CI: $0.07-2.16$ versus voglibose: +0.98 , 95\% CI: 0.04-1.91), and there was no significant difference in $\triangle$ FMD between the two groups (Table 2 and Figure 2).

\section{Secondary efficacy measures}

There were no significant differences in changes in HbA1c, GIP, GLP-1, C-peptide, lipid profile, oxidative stress marker, inflammatory marker and eGFR between the two groups (Table 3). Sitagliptin tended to increase GLP-1 levels after 12 weeks of treatment ( 0 week: $5.71 \pm$ 5.92 versus 12 weeks: $8.25 \pm 6.37 \mathrm{pmol} / \mathrm{L}, \mathrm{P}=0.0611$ ), but voglibose did not change the levels (0 week: $6.65 \pm$
10.18 versus 12 weeks: $6.66 \pm 6.15 \mathrm{pmol} / \mathrm{L}, \mathrm{P}=0.9973)$. Compared with voglibose, sitagliptin significantly increased circulating CD34, a marker of positive endothelial progenitor cells $(\mathrm{P}<0.05)$ (Table 3 and Figure 3$)$.

\section{Adverse events}

Adverse events were observed in 5 patients in the voglibose group (Table 4). There were no serious side effects in either group.

\section{Discussion}

In summary, $\triangle F M D$ was significantly improved after 12 weeks of treatment in both the sitagliptin and voglibose groups, and there was no significant difference in $\triangle F M D$ between the two groups.

Alpha GI improves postprandial endothelial dysfunction in patients with type 2 diabetes $[9,10]$. We showed that not only voglibose, an alpha GI, but also sitagliptin, a DPP-4 inhibitor, improves endothelial function as assessed by FMD in patients with type 2 diabetes. The impact of a DPP-4 inhibitor on endothelial dysfunction in patients with type 2 diabetes is controversial. A recent study showed that sitagliptin improved endothelial dysfunction assessed by the reactive hyperemia arterial tonometry index (RHI) after 6 months of treatment in patients with diabetes and coronary artery disease [24]. We also showed that sitagliptin improved endothelial dysfunction assessed by another method, FMD. A prospective observational single arm trial also showed that the treatment with sitagliptin for 12 weeks increased FMD in patients with type 2 diabetes [36]. Here, we conducted a randomized prospective multicenter study in patients with type 2 diabetes and revealed improvement of FMD after the 12-week treatment with sitagliptin. In contrast, another short-term study showed that DPP-4 inhibitors, including sitagliptin or alogliptin, attenuated endothelial function as evaluated by FMD after 6 weeks of treatment in patients with diabetes [19]. Furthermore, voglibose, an alpha GI, did not affect FMD in the study. Therefore, short-term treatment with either DPP-4 inhibitors or alpha GI does not ameliorate endothelial dysfunction in patients with diabetes. Our study showed that 12-week treatment with either sitagliptin or voglibose ameliorated endothelial function. Thus, at least 12 weeks of treatment is needed to improve endothelial function.

The STOP-NIDDM trial showed that an alpha GI reduces the risk of cardiovascular events in patients with IGT [12]. DPP-4 inhibitors are also expected to have beneficial cardiovascular effects [37,38]. However, two recent trials with DPP-4 inhibitors, SAVOR-TIMI 53 and EXAMINE trials, showed that saxagliptin and alogliptin did not increase or decrease ischemic events in patients with type 2 diabetes $[39,40]$. These trials demonstrated the safety of DPP-4 inhibitors but did not 
Table 1 Baseline clinical characteristics

\begin{tabular}{|c|c|c|c|}
\hline Variables & $\begin{array}{l}\text { Sitagliptin, } \\
\mathrm{n}=\mathbf{2 4}\end{array}$ & $\begin{array}{l}\text { Voglibose, } \\
\mathrm{n}=31\end{array}$ & $P$ value \\
\hline Age, y & $66.6 \pm 11.9$ & $68.4 \pm 9.2$ & 0.529 \\
\hline Male & $10(41.7 \%)$ & $18(58.1 \%)$ & 1.000 \\
\hline Diabetes duration, $\mathrm{m}$ & $57.6 \pm 41.2$ & $41.9 \pm 44.1$ & 0.075 \\
\hline $\mathrm{BMl}, \mathrm{kg} / \mathrm{m}^{2}$ & $27.8 \pm 3.5$ & $25.7 \pm 4.3$ & 0.061 \\
\hline Abdominal girth, $\mathrm{cm}$ & $91.4 \pm 11.1$ & $85.6 \pm 17.4$ & 0.303 \\
\hline Current smoking & $5(20.8 \%)$ & $5(16.1 \%)$ & 0.475 \\
\hline $\begin{array}{l}\text { Regular alcohol } \\
\text { drinkers }\end{array}$ & $4(16.7 \%)$ & $9(29.0 \%)$ & 0.349 \\
\hline Diabetic complication & $1(4.2 \%)$ & $2(6.5 \%)$ & 1.000 \\
\hline Diabetic retinopathy & $1(4.2 \%)$ & $0(0 \%)$ & 0.436 \\
\hline Diabetic nephropathy & $0(0 \%)$ & $2(6.5 \%)$ & 0.499 \\
\hline Diabetic neuropathy & $0(0 \%)$ & $0(0 \%)$ & - \\
\hline Hypertension & $20(83.3 \%)$ & 25 (80.6\%) & 1.000 \\
\hline Hyperlipidemia & $15(62.5 \%)$ & $18(58.1 \%)$ & 0.787 \\
\hline Hyperuricemia & $4(16.7 \%)$ & $2(6.5 \%)$ & 0.387 \\
\hline Renal disturbance & $3(12.5 \%)$ & $2(3.2 \%)$ & 0.307 \\
\hline $\begin{array}{l}\text { Established Cardiovascular } \\
\text { diseases }\end{array}$ & $7(29.2)$ & $7(22.6)$ & 0.756 \\
\hline Cerebrovascular disease & $4(16.7 \%)$ & $1(3.2 \%)$ & 0.156 \\
\hline Myocardial infarction & $3(12.5 \%)$ & $5(16.1 \%)$ & 1.000 \\
\hline Peripheral artery disease & $2(8.3 \%)$ & $1(3.2 \%)$ & 0.575 \\
\hline \multicolumn{4}{|l|}{ Antidiabetic drugs } \\
\hline Pioglitazone & $11(45.8)$ & 16 (51.6\%) & 0.787 \\
\hline Sulfonylurea & $5(20.8 \%)$ & $3(9.7 \%)$ & 0.276 \\
\hline Metformin & $3(12.5 \%)$ & $0(0 \%)$ & 0.077 \\
\hline \multicolumn{4}{|l|}{ Antihypertensive drugs } \\
\hline ARB & $15(62.5 \%)$ & 19 (61.3\%) & 1.000 \\
\hline CCB & $13(54.2 \%)$ & $18(58.1 \%)$ & 0.791 \\
\hline Diuretics & $9(37.5 \%)$ & $10(32.3 \%)$ & 0.778 \\
\hline Others & $11(45.8 \%)$ & $12(38.7 \%)$ & 0.783 \\
\hline ACE-I & $1(4.2 \%)$ & $3(9.7 \%)$ & \\
\hline a-Blocker & $4(16.7 \%)$ & $3(9.7 \%)$ & \\
\hline$\beta$-Blocker & $3(12.5 \%)$ & $5(16.1 \%)$ & \\
\hline aß-Blocker & $1(4.2 \%)$ & $1(3.2 \%)$ & \\
\hline Aldosterone antagonist & $2(8.3 \%)$ & $0(0 \%)$ & \\
\hline Antihyperlipidemic drugs & $2(8.3 \%)$ & $0(0 \%)$ & \\
\hline Statins & $12(50.0 \%)$ & $14(45.2 \%)$ & 0.789 \\
\hline Fibrate & $2(8.3 \%)$ & $2(6.5 \%)$ & 1.000 \\
\hline Ezetimibe & $3(12.5 \%)$ & $6(19.4 \%)$ & 0.716 \\
\hline Eicosapentaenoic acid & $2(8.3 \%)$ & $3(9.7 \%)$ & 1.000 \\
\hline \multicolumn{4}{|l|}{ Antithrombogenic agents } \\
\hline Antiplatelet agent & $16(66.7 \%)$ & $17(54.8 \%)$ & 0.417 \\
\hline Anticoagulant agent & $2(8.3 \%)$ & $0(0.0 \%)$ & 0.186 \\
\hline
\end{tabular}

Table 1 Baseline clinical characteristics (Continued)

\begin{tabular}{llll}
\hline Nitrates & $3(12.5 \%)$ & $0(0 \%)$ & 0.077 \\
Allopurinol & $1(4.2 \%)$ & $1(3.2 \%)$ & 1.000 \\
Uricosuric agents & $0(0 \%)$ & $1(3.2 \%)$ & 1.000 \\
\hline
\end{tabular}

ARB: angiotensin receptor blocker, CCB: calcium channel blocker, ACE-I: Angiotensin-converting enzyme inhibitor. Data are expressed as mean $\pm \mathrm{SD}$ or as a number (percentage).

demonstrate cardiovascular benefits. Patients at high risk patients for cardiovascular disease were enrolled in those studies. In the SAVOR-TIMI 53 trial, about $78 \%$ of the patients had established cardiovascular disease, and the EXAMINE trial consisted of patients with acute coronary syndrome. Mean HbA1c levels were about 8.0 in patients of those studies. Our study included relatively low-risk patients. Only about $25 \%$ of the patients in our study had established cardiovascular diseases. Mean HbA1c levels were about 7.0. $\triangle \mathrm{FMD}$ was significantly improved after 12 weeks of treatment in both the sitagliptin and voglibose groups in our study. The clinical implication of this study is the demonstration of beneficial effects of both sitagliptin and voglibose on endothelial dysfunction in low-risk and mild-risk patients with type 2 diabetes. Therefore, sitagliptin and voglibose might have cardiovascular benefits in low-risk and mild-risk patients with type 2 diabetes. Further studies are needed to clarify the long-term benefits for cardiovascular disease [37].

Iwamoto et al. reported that once-daily sitagliptin monotherapy (50 mg/day) showed greater efficacy and better tolerability than did thrice-daily voglibose $(0.6 \mathrm{mg} /$ day $)$ over 12 weeks in Japanese patients with type 2 diabetes [41], but there was no significant difference in changes in HbA1c between the sitagliptin $(50 \mathrm{mg} /$ day $)$ and voglibose $(0.6 \mathrm{mg} /$ day $)$ groups in our

Table 2 Changes in FMD ( $\triangle F M D$ ) in the sitagliptin and voglibose group

\begin{tabular}{llll}
\hline Variable & $\begin{array}{l}\text { Sitagliptin } \\
\mathbf{n = 2 4}\end{array}$ & $\begin{array}{l}\text { Voglibose } \\
\mathbf{n = 3 1}\end{array}$ & $\begin{array}{l}\text { Between-group } \\
\text { difference }\end{array}$ \\
\hline FMD (\%) & & & \\
Baseline at 0 W & $5.41 \pm 2.25$ & $4.96 \pm 2.16$ & $\mathrm{P}=0.450$ \\
at 12 W & $6.17 \pm 2.00$ & $5.94 \pm 2.15$ & $\mathrm{P}=0.692$ \\
$\quad$ FMD:12 W-0 W & $0.76 \pm 2.42$ & $0.98 \pm 2.41$ & $\mathrm{P}=0.729$ \\
Adjusted $\Delta$ FMD:12 W-0 W* & 1.11 & 0.98 & $\mathrm{P}=0.8316$ \\
$\quad$ (95\% Cls) & $(0.07-2.16)$ & $(0.04-1.91)$ & \\
\hline
\end{tabular}

Values are means \pm SD or the least square means $(95 \% \mathrm{Cl})$. ${ }^{*}$ The least square means $(95 \% \mathrm{Cls}$ ) were derived from ANCOVA adjusted for the baseline FMD, age, sex, current smoking, diabetes duration and BMI. 
Table 3 Changes in secondary efficacy measures in the sitagliptin and voglibose groups

\begin{tabular}{|c|c|c|c|c|c|}
\hline \multirow[b]{2}{*}{ Variable } & \multicolumn{2}{|l|}{ Sitagliptin } & \multicolumn{2}{|l|}{ Voglibose } & \multirow{2}{*}{$\begin{array}{l}\text { Between-group difference } \\
\text { P value }\end{array}$} \\
\hline & $\overline{\text { mean } \pm S D}$ & $P$ value & $\overline{\text { mean } \pm S D}$ & $P$ value & \\
\hline \multicolumn{6}{|l|}{$\mathrm{HbA1C}$} \\
\hline baseline at $0 \mathrm{~W}$ & $7.04 \pm 0.56$ & & $6.94 \pm 0.45$ & & \\
\hline at $12 \mathrm{~W}$ & $6.65 \pm 0.57$ & & $6.59 \pm 0.45$ & & \\
\hline $12 \mathrm{~W}-0 \mathrm{~W}$ & $-0.39 \pm 0.60$ & 0.0051 & $-0.35 \pm 0.39$ & $<0.0001$ & 0.8021 \\
\hline \multicolumn{6}{|l|}{ GIP } \\
\hline baseline at $0 \mathrm{~W}$ & $289.92 \pm 326.04$ & & $214.21 \pm 220.15$ & & \\
\hline at $12 \mathrm{~W}$ & $246.50 \pm 284.25$ & & $258.41 \pm 226.88$ & & \\
\hline $12 \mathrm{~W}-0 \mathrm{~W}$ & $-43.42 \pm 190.10$ & 0.3077 & $44.20 \pm 198.54$ & 0.2671 & 0.1323 \\
\hline \multicolumn{6}{|l|}{ GLP-1 } \\
\hline baseline at $0 \mathrm{~W}$ & $5.71 \pm 5.92$ & & $6.65 \pm 10.18$ & & \\
\hline at $12 \mathrm{~W}$ & $8.25 \pm 6.37$ & & $6.66 \pm 6.15$ & & \\
\hline $12 \mathrm{~W}-0 \mathrm{~W}$ & $2.54 \pm 5.71$ & 0.0611 & $0.00 \pm 5.70$ & 0.9973 & 0.1418 \\
\hline \multicolumn{6}{|l|}{ C-peptide } \\
\hline baseline at $0 \mathrm{~W}$ & $3.913 \pm 2.567$ & & $3.037 \pm 1.629$ & & \\
\hline at $12 \mathrm{~W}$ & $3.909 \pm 2.410$ & & $3.571 \pm 2.710$ & & \\
\hline $12 \mathrm{~W}-0 \mathrm{~W}$ & $-0.003 \pm 1.366$ & 0.9906 & $0.534 \pm 2.712$ & 0.2977 & 0.3555 \\
\hline \multicolumn{6}{|l|}{ CD34 } \\
\hline baseline at $0 \mathrm{~W}$ & $0.956 \pm 0.563$ & & $0.896 \pm 0.622$ & & \\
\hline at $12 \mathrm{~W}$ & $1.134 \pm 0.615$ & & $0.847 \pm 0.470$ & & \\
\hline $12 \mathrm{~W}-0 \mathrm{~W}$ & $0.178 \pm 0.379$ & 0.0311 & $-0.050 \pm 0.368$ & 0.4656 & 0.0304 \\
\hline \multicolumn{6}{|l|}{ Total cholesterol } \\
\hline baseline at $0 \mathrm{~W}$ & $181.6 \pm 28.8$ & & $187.8 \pm 38.9$ & & \\
\hline at $12 \mathrm{~W}$ & $172.5 \pm 28.2$ & & $183.9 \pm 46.6$ & & \\
\hline $12 \mathrm{~W}-0 \mathrm{~W}$ & $-9.0 \pm 21.5$ & 0.0509 & $-3.9 \pm 30.0$ & 0.4865 & 0.4807 \\
\hline \multicolumn{6}{|l|}{ Triglyceride } \\
\hline baseline at $0 \mathrm{~W}$ & $158.9 \pm 131.1$ & & $141.2 \pm 68.4$ & & \\
\hline at $12 \mathrm{~W}$ & $122.4 \pm 60.9$ & & $119.2 \pm 51.9$ & & \\
\hline $12 \mathrm{~W}-0 \mathrm{~W}$ & $-36.5 \pm 98.8$ & 0.0837 & $-22.1 \pm 52.0$ & 0.0249 & 0.5217 \\
\hline \multicolumn{6}{|l|}{$\mathrm{HDL}-\mathrm{C}$} \\
\hline baseline at $0 \mathrm{~W}$ & $56.4 \pm 16.8$ & & $53.8 \pm 13.0$ & & \\
\hline at $12 \mathrm{~W}$ & $57.5 \pm 24.4$ & & $50.3 \pm 11.4$ & & \\
\hline $12 \mathrm{~W}-0 \mathrm{~W}$ & $1.0 \pm 20.9$ & 0.8096 & $-3.5 \pm 8.3$ & 0.0246 & 0.3223 \\
\hline \multicolumn{6}{|l|}{ adiponectin } \\
\hline baseline at $0 \mathrm{~W}$ & $13.80 \pm 12.88$ & & $15.15 \pm 13.81$ & & \\
\hline at $12 \mathrm{~W}$ & $13.11 \pm 11.10$ & & $14.09 \pm 8.76$ & & \\
\hline $12 \mathrm{~W}-0 \mathrm{~W}$ & $-0.69 \pm 2.71$ & 0.2260 & $-1.06 \pm 7.41$ & 0.4413 & 0.8020 \\
\hline \multicolumn{6}{|l|}{ MDA-LDL } \\
\hline baseline at $0 \mathrm{~W}$ & $98.7 \pm 32.0$ & & $112.4 \pm 44.3$ & & \\
\hline at $12 \mathrm{~W}$ & $99.7 \pm 44.5$ & & $116.6 \pm 49.7$ & & \\
\hline $12 \mathrm{~W}-0 \mathrm{~W}$ & $1.0 \pm 33.8$ & 0.8812 & $4.2 \pm 45.0$ & 0.6156 & 0.7787 \\
\hline \multicolumn{6}{|l|}{$8-\mathrm{OHdG}$} \\
\hline baseline at $0 \mathrm{~W}$ & $12.20 \pm 6.55$ & & $12.31 \pm 8.88$ & & \\
\hline at $12 \mathrm{~W}$ & $13.10 \pm 7.39$ & & $12.43 \pm 15.46$ & & \\
\hline
\end{tabular}


Table 3 Changes in secondary efficacy measures in the sitagliptin and voglibose groups (Continued)

\begin{tabular}{|c|c|c|c|c|c|}
\hline $12 \mathrm{~W}-0 \mathrm{~W}$ & $0.90 \pm 7.30$ & 0.5533 & $0.12 \pm 17.29$ & 0.9699 & 0.8252 \\
\hline \multicolumn{6}{|l|}{ hs-CRP } \\
\hline baseline at $0 \mathrm{~W}$ & $2194.4 \pm 4079.1$ & & $2052.2 \pm 3816.2$ & & \\
\hline at $12 \mathrm{~W}$ & $1202.0 \pm 1424.2$ & & $3322.7 \pm 7813.6$ & & \\
\hline $12 \mathrm{~W}-0 \mathrm{~W}$ & $-992.4 \pm 3609.6$ & 0.1911 & $1270.5 \pm 5592.1$ & 0.2233 & 0.0783 \\
\hline \multicolumn{6}{|l|}{ PTX-3 } \\
\hline baseline at $0 \mathrm{~W}$ & $1.606 \pm 0.733$ & & $2.461 \pm 2.989$ & & \\
\hline at $12 \mathrm{~W}$ & $1.491 \pm 0.585$ & & $1.848 \pm 0.790$ & & \\
\hline $12 \mathrm{~W}-0 \mathrm{~W}$ & $-0.115 \pm 0.462$ & 0.2334 & $-0.613 \pm 2.542$ & 0.1967 & 0.3012 \\
\hline \multicolumn{6}{|l|}{ e-GFR } \\
\hline baseline at $0 \mathrm{~W}$ & $66.8 \pm 20.8$ & & $63.6 \pm 20.8$ & & \\
\hline at $12 \mathrm{~W}$ & $62.2 \pm 17.8$ & & $61.4 \pm 19.9$ & & \\
\hline $12 \mathrm{~W}-0 \mathrm{~W}$ & $-4.6 \pm 9.7$ & 0.0301 & $-2.1 \pm 7.7$ & 0.1306 & 0.3007 \\
\hline
\end{tabular}

GIP: gastric inhibitory peptide, GLP-1: glucagon-like peptide-1, HDL-C: high density lipoprotein cholesterol, MDA-LDL: malondialdehyde-modified low density lipoprotein, 8-OHdG: 8-hydroxy-2'-deoxyguanosine, hs-CRP: high-sensitivity C-reactive protein, PTX-3: pentraxin-3, e-GFR: estimated glomerular filtration rate. Data are expressed as mean \pm SD.

study. Mean HbA1c levels at baseline in the former study and our study were about 7.8 and 7.0 , respectively. Lower HbA1c at baseline in our study might have had an influence on changes in HbA1c levels. Sitagliptin tended to increase GLP-1 levels after 12 weeks of treatment, but there was no significant difference in changes in GIP and GLP-1 between the two groups in this study. These results might be because of the small sample size.

Matsubara et al. reported that treatment with sitagliptin for 6 months improved endothelial dysfunction along with a decrease in hs-CRP in patients with coronary

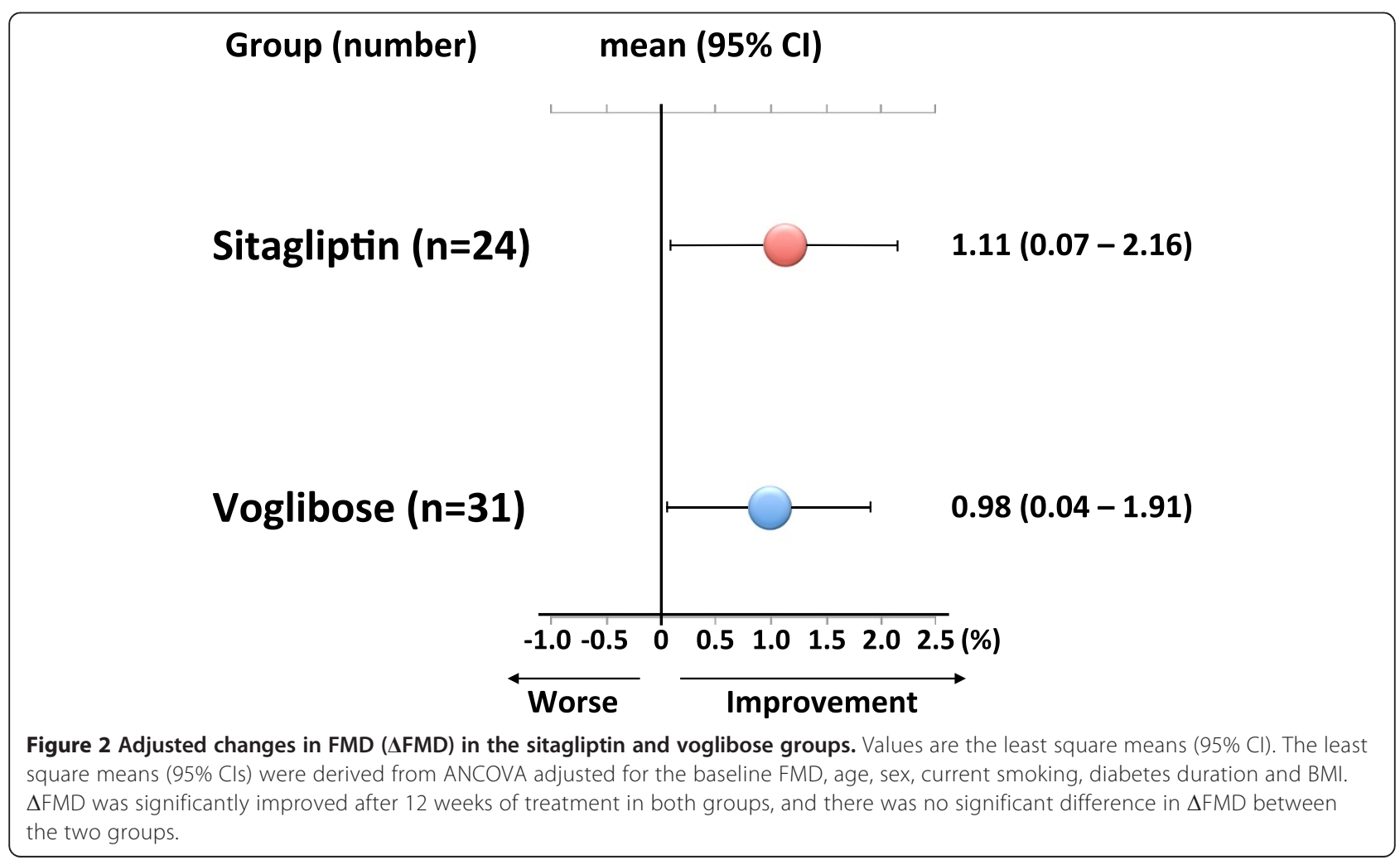



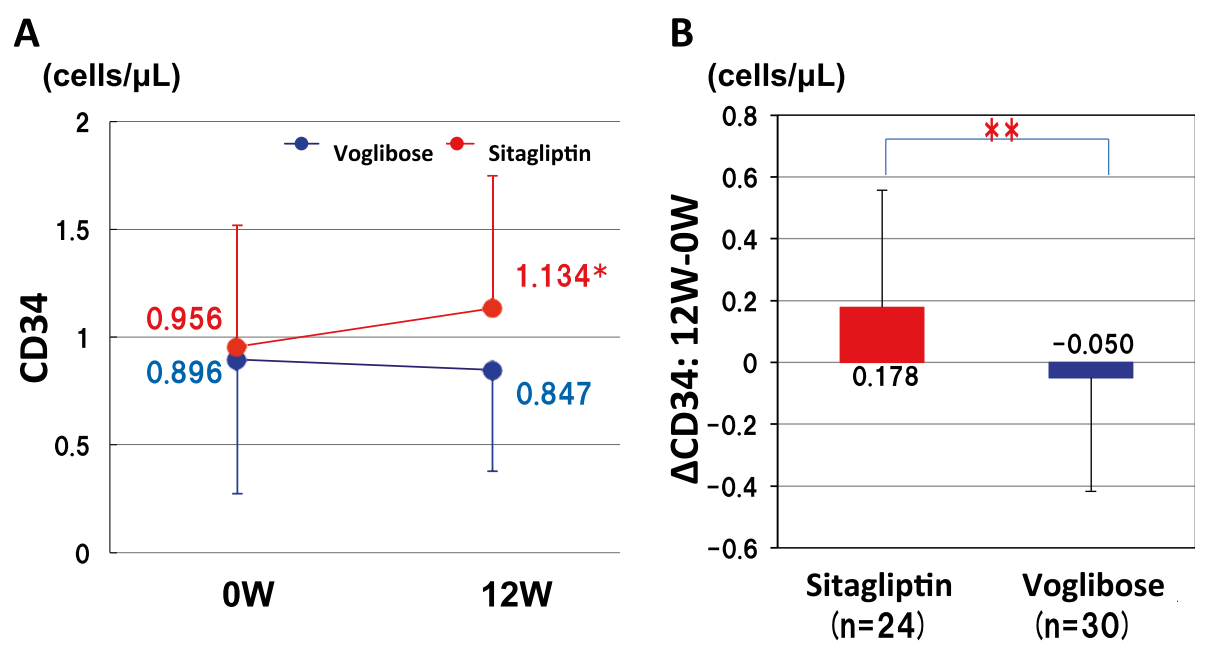

Figure $\mathbf{3}$ Changes in CD34 in the sitagliptin and voglibose groups. A. Circulating CD34 levels at 0 week and 12 weeks in the sitagliptin and voglibose groups. ${ }^{*} \mathrm{P}<0.05$ vs. $0 \mathrm{~W}$, paired t-test. $\mathbf{B}$. Change in CD34 from the baseline to the end of follow-up $(\Delta C D 34) .{ }^{*} \mathrm{P}<0.05$, Student's t-test.

artery disease and uncontrolled diabetes [24]. Lipid profiles and eGFR did not change after treatment with sitagliptin in that study as well as in our study. Our study showed no significant difference in changes in hs-CRP after treatment with sitagliptin. Furthermore, Sakamoto et al. reported that sitagliptin improved blood pressure and lipid profiles in patients with type 2 diabetes [42]. These different results might be due to the small sample size, short-term treatment or study in low risk patients with type 2 diabetes.

Fadini et al. reported that sitagliptin increased circulating EPCs in type 2 diabetic patients with concomitant upregulation of stromal-derived factor- $1 \alpha$ $(\mathrm{SDF}-1 \alpha)$ [21]. SDF- $1 \alpha$ is a chemokine that stimulates bone marrow mobilization of EPCs and is one of the substrates of DPP-4. We also showed that sitagliptin significantly increased circulating CD34, but voglibose did not increase CD34. Therefore, this is an ancillary effect of sitagliptin and it is independent from blood glucose levels. Liao et al. reported that the number of EPCs was an independent risk

Table 4 Adverse events

\begin{tabular}{lll}
\hline Events & $\begin{array}{l}\text { Sitagliptin } \\
\mathbf{n = 2 9}\end{array}$ & $\begin{array}{l}\text { Voglibose } \\
\mathbf{n = 3 4}\end{array}$ \\
\hline Diarrhea & $0(0 \%)$ & $1(2.9 \%)$ \\
Nausea & $0(0 \%)$ & $1(2.9 \%)$ \\
Edema & $0(0 \%)$ & $2(5.9 \%)$ \\
Abdominal fullness & $0(0 \%)$ & $1(2.9 \%)$ \\
\hline
\end{tabular}

Number of cases (\%) is shown. factor for FMD [20]. Thus, this effect might be favorable for the preservation of endothelial function in the future. Further long-term studies are needed to clarify this point.

A recent study revealed that alogliptin, a DPP- 4 inhibitor, did not increase the frequency of serious adverse events, including hypoglycemia, cancer, pancreatitis, and initiation of dialysis in patients with type 2 diabetes who had a recent acute coronary syndrome [40]. A pooled analysis of 25 randomized clinical trials did not indicate that treatment with sitagliptin increases cardiovascular risk in patients with type 2 diabetes mellitus [43]. Our study also showed that sitagliptin did not cause serious adverse events. Thus, DPP-4 inhibitors may be safe drugs for patients with type 2 diabetes.

\section{Study limitations}

The first limitation of this study was the small sizes of the groups. The second was heterogeneity of the population in this study. The age range was quite wide in our study. The third limitation was that our study was a short-term study. Our findings need to be confirmed in a large cohort of patients with type 2 diabetes and with a long period.

In conclusion, sitagliptin improves endothelial dysfunction just as well as voglibose in patients with type 2 diabetes. Furthermore, sitagliptin increases the level of circulating CD34. Sitagliptin has protective effects on endothelial function without adverse events. These effects have potential favorable cardiovascular implications for patients with type 2 diabetes. 


\section{Abbreviations}

BMI: Body mass index; DPP-4: Dipeptidyl peptidase IV; eGFR: Estimated glomerular filtration rate; FMD: Flow-mediated dilatation; GIP: Gastric inhibitory peptide; GLP-1: Glucagon-like peptide-1; Gl: Glucosidase inhibitor; hs-CRP: High-sensitivity C-reactive protein; 8-OHdG: 8-hydroxy-2'deoxyguanosine; IGT: Impaired glucose tolerance; MDA-

LDL: Malondialdehyde-modified low density lipoprotein; PTX-3: Pentraxin-3; PPH: Postprandial hyperglycemia.

\section{Competing interests}

The authors declare that they have no competing interest.

\section{Authors' contributions}

$\mathrm{KN}, \mathrm{YJ}, \mathrm{HI}$ conceived the study, and participated in its design and coordination and helped to draft the manuscript. KN, HO, HK, KS, SF, KW, TT, $\mathrm{KY}, \mathrm{TM}, \mathrm{KH}$ carried out examinations. All authors read and approved the final manuscript.

\section{Acknowledgements}

This study was supported by Osaka Foundation for the prevention of cancer and cardiovascular diseases. The authors also thank the EDGE study investigators: Kazufumi Nakamura, MD; Hiroki Oe, MD; Kei Yunoki, MD; Toru Miyoshi, MD, Hiroshi Ito, MD (Okayama University, Okayama, Japan), Hajime Kihara, MD (Kihara Cardiovascular Clinic), Kenei Shimada, MD (Osaka City University of Medicine), Shota Fukuda, MD (Osaka Ekisaikai Hospital), Kyoko Watanabe, MD (Okayama Saiseikai Hospital), Tsutomu Takagi, MD (Takagi Cardiology Clinic), Kumiko Hirata, MD (Wakayama Medical University) and Junichi Yoshikawa, MD (Nishinomiya Watanabe Cardiovascular Center).

\section{Author details}

'Department of Cardiovascular Medicine, Okayama University Graduate School of Medicine, Dentistry and Pharmaceutical Sciences, 2-5-1 Shikata-cho, Okayama 700-8558, Japan. ${ }^{2}$ Department of Internal Medicine, Kihara Cardiovascular Clinic, Asahikawa, Japan. ${ }^{3}$ Department of Internal Medicine and Cardiology, Osaka City University of Medicine, Osaka, Japan. ${ }^{4}$ Department of Medicine, Osaka Ekisaikai Hospital, Osaka, Japan. ${ }^{5}$ Department of Internal Medicine, Okayama Saiseikai General Hospital, Okayama, Japan. ${ }^{6}$ Takagi Cardiology Clinic, Kyoto, Japan. ${ }^{7}$ Department of Cardiovascular Medicine, Wakayama Medical University, Wakayama, Japan. ${ }^{8}$ Nishinomiya Watanabe Cardiovascular Center, Nishinomiya, Japan.

Received: 13 December 2013 Accepted: 29 June 2014

Published: 30 July 2014

\section{References}

1. Hanefeld M, Fischer S, Julius U, Schulze J, Schwanebeck U, Schmechel H, Ziegelasch HJ, Lindner J: Risk factors for myocardial infarction and death in newly detected NIDDM: the Diabetes Intervention Study, 11-year follow-up. Diabetologia 1996, 39(12):1577-1583.

2. DECODE-Study-Group: Is the current definition for diabetes relevant to mortality risk from all causes and cardiovascular and noncardiovascular diseases? Diabetes Care 2003, 26(3):688-696.

3. Kawano H, Motoyama T, Hirashima O, Hirai N, Miyao Y, Sakamoto T, Kugiyama K, Ogawa H, Yasue H: Hyperglycemia rapidly suppresses flow-mediated endothelium-dependent vasodilation of brachial artery. J Am Coll Cardiol 1999, 34(1):146-154.

4. Wascher TC, Schmoelzer I, Wiegratz A, Stuehlinger M, Mueller-Wieland D, Kotzka J, Enderle M: Reduction of postchallenge hyperglycaemia prevents acute endothelial dysfunction in subjects with impaired glucose tolerance. Eur J Clin Invest 2005, 35(9):551-557.

5. Martin AE, Montgomery PA: Acarbose: an alpha-glucosidase inhibitor. Am J Health Syst Pharm 1996, 53(19):2277-2290. quiz 2336-2277.

6. Chiasson JL, Josse RG, Gomis R, Hanefeld M, Karasik A, Laakso M: Acarbose for prevention of type 2 diabetes mellitus: the STOP-NIDDM randomised trial. Lancet 2002, 359(9323):2072-2077.

7. Hiki M, Shimada K, Kiyanagi T, Fukao K, Hirose K, Ohsaka H, Fukushima Y, Kume A, Matsumori R, Sumiyoshi K, Miyazaki T, Ohmura H, Kurata T, Miida T, Daida $\mathrm{H}$ : Single administration of alpha-glucosidase inhibitors on endothelial function and incretin secretion in diabetic patients with coronary artery disease - Juntendo University trial: effects of miglitol on endothelial vascular reactivity in type 2 diabetic patients with coronary heart disease (J-MACH). Circ J 2010, 74(7):1471-1478.

8. Emoto T, Sawada T, Hashimoto M, Kageyama H, Terashita D, Mizoguchi T, Mizuguchi T, Motodi Y, Iwasaki M, Taira K, Okamoto H, Matsuo Y, Kim SK, Takarada A, Yokoyama M: Effect of 3-month repeated administration of miglitol on vascular endothelial function in patients with diabetes mellitus and coronary artery disease. Am J Cardiol 2012, 109(1):42-46.

9. Shimabukuro M, Higa N, Chinen I, Yamakawa K, Takasu N: Effects of a single administration of acarbose on postprandial glucose excursion and endothelial dysfunction in type 2 diabetic patients: a randomized crossover study. J Clin Endocrinol Metab 2006, 91(3):837-842.

10. Kato $T$, Inoue $T$, Node $K$ : Postprandial endothelial dysfunction in subjects with new-onset type 2 diabetes: an acarbose and nateglinide comparative study. Cardiovasc Diabetol 2010, 9:12.

11. Hanefeld M, Cagatay M, Petrowitsch T, Neuser D, Petzinna D, Rupp M: Acarbose reduces the risk for myocardial infarction in type 2 diabetic patients: meta-analysis of seven long-term studies. Eur Heart J 2004, 25(1):10-16

12. Chiasson JL, Josse RG, Gomis R, Hanefeld M, Karasik A, Laakso M: Acarbose treatment and the risk of cardiovascular disease and hypertension in patients with impaired glucose tolerance: the STOP-NIDDM trial. JAMA 2003, 290(4):486-494.

13. Hanefeld M, Schaper F, Koehler C: Effect of acarbose on vascular disease in patients with abnormal glucose tolerance. Cardiovasc Drugs Ther 2008, 22(3):225-231.

14. Seo C, Sakamoto M, Nishimura R, Tsujino D, Ando K, Morimoto A, Utsunomiya K: Comparison of glycemic variability in patients with type 2 diabetes given sitagliptin or voglibose: a continuous glucose monitoring-based pilot study. Diabetes Technol Ther 2013, 15(5):378-385.

15. Anagnostis $P$, Athyros VG, Adamidou F, Panagiotou A, Kita M, Karagiannis A, Mikhailidis DP: Glucagon-like peptide-1-based therapies and cardiovascular disease: looking beyond glycaemic control. Diabetes Obes Metab 2011, 13(4):302-312.

16. Nystrom T, Gutniak MK, Zhang Q, Zhang F, Holst JJ, Ahren B, Sjoholm A: Effects of glucagon-like peptide-1 on endothelial function in type 2 diabetes patients with stable coronary artery disease. Am J Physiol Endocrinol Metab 2004, 287(6):E1209-E1215.

17. Liu L, Liu J, Wong WT, Tian XY, Lau CW, Wang YX, Xu G, Pu Y, Zhu Z, Xu A, Lam KS, Chen ZY, Ng CF, Yao X, Huang Y: Dipeptidyl peptidase 4 inhibitor sitagliptin protects endothelial function in hypertension through a glucagon-like peptide 1-dependent mechanism. Hypertension 2012, 60(3):833-841.

18. Pistrosch F, Schaper F, Passauer J, Koehler C, Bornstein SR, Hanefeld M: Effects of the alpha glucosidase inhibitor acarbose on endothelial function after a mixed meal in newly diagnosed type 2 diabetes. Horm Metab Res 2009, 41(2):104-108.

19. Ayaori M, Iwakami N, Uto-Kondo H, Sato H, Sasaki M, Komatsu T, lizuka M, Takiguchi S, Yakushiji E, Nakaya K, Yogo M, Ogura M, Takase B, Murakami T, Ikewaki K: Dipeptidyl peptidase-4 inhibitors attenuate endothelial function as evaluated by flow-mediated vasodilatation in type 2 diabetic patients. J Am Heart Assoc 2013, 2(1):e003277.

20. Liao YF, Chen LL, Zeng TS, Li YM, Fan Y, Hu LJ, Ling Y: Number of circulating endothelial progenitor cells as a marker of vascular endothelial function for type 2 diabetes. Vasc Med 2010, 15(4):279-285.

21. Fadini GP, Boscaro E, Albiero M, Menegazzo L, Frison V, de Kreutzenberg S, Agostini C, Tiengo A, Avogaro A: The oral dipeptidyl peptidase-4 inhibitor sitagliptin increases circulating endothelial progenitor cells in patients with type 2 diabetes: possible role of stromal-derived factor-1alpha. Diabetes Care 2010, 33(7):1607-1609.

22. Mackie AR, Losordo DW: CD34-positive stem cells: in the treatment of heart and vascular disease in human beings. Tex Heart Inst J 2011, 38(5):474-485

23. Ishibashi Y, Matsui T, Maeda S, Higashimoto Y, Yamagishi S: Advanced glycation end products evoke endothelial cell damage by stimulating soluble dipeptidyl peptidase-4 production and its interaction with mannose 6-phosphate/insulin-like growth factor II receptor. Cardiovasc Diabetol 2013, 12:125.

24. Matsubara J, Sugiyama S, Akiyama E, Iwashita S, Kurokawa H, Ohba K, Maeda H, Fujisue K, Yamamoto E, Kaikita K, Hokimoto S, Jinnouchi H, Ogawa H: Dipeptidyl peptidase-4 inhibitor, sitagliptin, improves endothelial dysfunction in association with its anti-inflammatory 
effects in patients with coronary artery disease and uncontrolled diabetes. Circ J 2013, 77(5):1337-1344.

25. Shiraki A, Oyama J, Komoda H, Asaka M, Komatsu A, Sakuma M, Kodama K Sakamoto Y, Kotooka N, Hirase T, Node K: The glucagon-like peptide 1 analog liraglutide reduces TNF-alpha-induced oxidative stress and inflammation in endothelial cells. Atherosclerosis 2012, 221(2):375-382.

26. I wamoto Y, Taniguchi T, Nonaka K, Okamoto T, Okuyama K, Arjona Ferreira $J C$, Amatruda J: Dose-ranging efficacy of sitagliptin, a dipeptidyl peptidase-4 inhibitor, in Japanese patients with type 2 diabetes mellitus. Endocr J 2010, 57(5):383-394.

27. Matsumoto K, Yano M, Miyake S, Ueki Y, Yamaguchi Y, Akazawa S, Tominaga Y: Effects of voglibose on glycemic excursions, insulin secretion, and insulin sensitivity in non-insulin-treated NIDDM patients. Diabetes Care 1998, 21(2):256-260.

28. Matsuo S, Imai E, Horio M, Yasuda Y, Tomita K, Nitta K, Yamagata K, Tomino Y, Yokoyama H, Hishida A: Revised equations for estimated GFR from serum creatinine in Japan. Am J Kidney Dis 2009, 53(6):982-992.

29. Corretti MC, Anderson TJ, Benjamin EJ, Celermajer D, Charbonneau F, Creager MA, Deanfield J, Drexler H, Gerhard-Herman M, Herrington D, Vallance P, Vita J, Vogel R: Guidelines for the ultrasound assessment of endothelial-dependent flow-mediated vasodilation of the brachial artery: a report of the International Brachial Artery Reactivity Task Force. J Am Coll Cardiol 2002, 39(2):257-265.

30. Yunoki K, Nakamura K, Miyoshi T, Enko K, Kohno K, Morita H, Kusano KF, Ito $\mathrm{H}$ : Ezetimibe improves postprandial hyperlipemia and its induced endothelial dysfunction. Atherosclerosis 2011, 217(2):486-491.

31. Yunoki K, Nakamura K, Miyoshi T, Enko K, Kubo M, Murakami M, Hata Y, Kohno K, Morita H, Kusano KF, Ito H: Impact of hypertriglyceridemia on endothelial dysfunction during statin +/-ezetimibe therapy in patients with coronary heart disease. Am J Cardiol 2011, 108(3):333-339.

32. Noda Y, Miyoshi T, Oe H, Ohno Y, Nakamura K, Toh N, Kohno K, Morita H, Kusano K, Ito H: Alogliptin ameliorates postprandial lipemia and postprandial endothelial dysfunction in non- diabetic subjects: a preliminary report. Cardiovasc Diabetol 2013, 12(1):8.

33. Charakida M, de Groot E, Loukogeorgakis SP, Khan T, Luscher T, Kastelein JJ, Gasser T, Deanfield JE: Variability and reproducibility of flow-mediated dilatation in a multicentre clinical trial. Eur Heart J 2013, 34(45):3501-3507.

34. Lind L: Impact of ageing on the measurement of endotheliumdependent vasodilation. Pharmacol Rep 2006, 58(Suppl):41-46.

35. Maruhashi T, Soga J, Fujimura N, Idei N, Mikami S, Iwamoto Y, Kajikawa M, Matsumoto T, Hidaka T, Kihara Y, Chayama K, Noma K, Nakashima A, Goto C, Tomiyama H, Takase B, Yamashina A, Higashi Y: Relationship between flow-mediated vasodilation and cardiovascular risk factors in a large community-based study. Heart 2013, 99(24):1837-1842.

36. Kubota Y, Miyamoto M, Takagi G, Ikeda T, Kirinoki-lchikawa S, Tanaka K Mizuno K: The dipeptidyl peptidase-4 inhibitor sitagliptin improves vascular endothelial function in type 2 diabetes. J Korean Med Sci 2012, 27(11):1364-1370.

37. Scheen AJ: Cardiovascular effects of dipeptidyl peptidase-4 inhibitors: from risk factors to clinical outcomes. Postgrad Med 2013, 125(3):7-20.

38. Hausenloy DJ, Whittington HJ, Wynne AM, Begum SS, Theodorou L, Riksen N, Mocanu MM, Yellon DM: Dipeptidyl peptidase-4 inhibitors and GLP-1 reduce myocardial infarct size in a glucose-dependent manner. Cardiovasc Diabetol 2013, 12(1):154.

39. Scirica BM, Bhatt DL, Braunwald E, Steg PG, Davidson J, Hirshberg B, Ohman P, Frederich R, Wiviott SD, Hoffman EB, Cavender MA, Udell JA, Desai NR, Mosenzon O, McGuire DK, Ray KK, Leiter LA, Raz I: Saxagliptin and cardiovascular outcomes in patients with type 2 diabetes mellitus. N Engl J Med 2013, 369(14):1317-1326.

40. White WB, Cannon CP, Heller SR, Nissen SE, Bergenstal RM, Bakris GL, Perez AT, Fleck PR, Mehta CR, Kupfer S, Wilson C, Cushman WC, Zannad F: Alogliptin after acute coronary syndrome in patients with type 2 diabetes. N Engl J Med 2013, 369(14):1327-1335.

41. Iwamoto Y, Tajima N, Kadowaki T, Nonaka K, Taniguchi T, Nishii M, Arjona Ferreira JC, Amatruda JM: Efficacy and safety of sitagliptin monotherapy compared with voglibose in Japanese patients with type 2 diabetes: a randomized, double-blind trial. Diabetes Obes Metab 2010, 12(7):613-622.
42. Sakamoto Y, Oyama J, Ikeda H, Kuroki S, Gondo S, Iwamoto T, Uchida Y, Kodama K, Hiwatashi A, Shimomura M, Taguchi I, Inoue T, Node K: Effects of sitagliptin beyond glycemic control: focus on quality of life. Cardiovasc Diabetol 2013, 12:35.

43. Engel SS, Golm GT, Shapiro D, Davies MJ, Kaufman KD, Goldstein BJ: Cardiovascular safety of sitagliptin in patients with type 2 diabetes mellitus: a pooled analysis. Cardiovasc Diabetol 2013, 12:3.

doi:10.1186/s12933-014-0110-2

Cite this article as: Nakamura et al.: DPP-4 inhibitor and alpha-glucosidase inhibitor equally improve endothelial function in patients with type 2 diabetes: EDGE study. Cardiovascular Diabetology 2014 13:110.

\section{Submit your next manuscript to BioMed Central and take full advantage of:}

- Convenient online submission

- Thorough peer review

- No space constraints or color figure charges

- Immediate publication on acceptance

- Inclusion in PubMed, CAS, Scopus and Google Scholar

- Research which is freely available for redistribution

Submit your manuscript at www.biomedcentral.com/submit
Ciomed Central 